\title{
METHODOLOGY FOR DEVELOPING AN AIR POLLUTION INDEX (API) FOR SOUTH AFRICA
}

\author{
Eugene Cairncross ${ }^{1}$ Juanette John $^{2}$, and Mark Zunckel ${ }^{3}$ \\ ${ }^{1}$ Peninsula Technikon, Box 1906, Bellville, 7535 \\ ${ }^{2}$ CSIR-Environmentek, PO Box 395, Pretoria, 0001 \\ ${ }^{3}$ CSIR Environmentek, P O Box 17001, Congella 4013, South Africa
}

\begin{abstract}
The Dynamic Air Pollution Prediction System (DAPPS) involves the development and integration of the following elements: Downscaling the current numerical urban-scale weather prediction to a finer spatial and temporal resolution, and establishing a comprehensive air pollutant emission inventory that will include industrial, motor vehicle and domestic emissions, and temporal variations in these emissions. The enhanced meteorological data and the emission inventory data will be used as inputs into a photochemical dispersion model, the Comprehensive Air Quality Model with Extensions (CAMx), to produce air pollution fields for the forecast meteorology.
\end{abstract}

Local air quality affects how we live and what we breathe. Like the weather, it can change from day to day sometimes from hour to hour. The known and recognized health effects of air pollution include the increased risk of the exacerbation of respiratory symptoms such as increased asthma attacks and reduced lung function, increased hospital admissions for respiratory and cardio-vascular diseases, and increased mortality. An Air Quality or Air Pollution Index (API) is a quantitative tool through which air pollution data can be reported, providing information on how clean or polluted the air is, and the associated health concerns the public should be aware of. These indices usually focus on short-term health effects - those that can happen within a few hours or days of exposure to polluted air. A key feature of the DAPPS is that the final model output is a set of Air Pollution Indices.

Several countries employ some type of air pollution index to communicate the quality of their air. Some of these systems rely on relating measured (monitored) or predicted concentrations of air pollutants to a numerical scale, for example ranging from 0 and 100. This scale may be enhanced by verbal descriptors such as high or moderate. The advantage of such a system is that the public does not have to interpret a number of different concentrations - one for each pollutant. They also do not need to recall that, the health effects of, for example $1 \mathrm{ppm}$ of ozone is very different from those of $1 \mathrm{ppm}$ of carbon monoxide.

The simplistic use of a single index to reflect air pollution levels creates several difficulties. Different pollutants may have different health endpoints, information that may be lost through the use of a single index. Members of the public may also find it difficult to obtain details of how to translate a unified pollution index back into the disaggregated 'real' pollutant levels. In addition, it can be difficult to use an index to compare pollutant levels with national or international standards or guidelines, or with indices used in other countries. The use of a single standardized or unified scale doesn't solve the problems of how to report raised concentrations of a number of pollutants.

The DAPPS proposes the development of a health-based Air Pollution Index as opposed to an Air Quality Index. The basic concept of this index is that of using a combination of modelled pollutant concentrations and exposure-response functions. The initial modelling output would be pollutant-specific numerical values indicating the degree of pollution in an area of the modelled domain. Normalising these values with exposure-response functions will result in normalised bands corresponding to a scale (for example, a scale of 1 to 10) and colour coding system that reflects the possible health impacts. Advice and information on possible health effects associated with each value on the scale would reflect information applicable to both the 'normal healthy' population and 'sensitive' groups within the exposed population (such as asthmatics, the aged or the very young). The index will be modified where possible to account for known additive and /or synergistic effects.

\section{Introduction}

In a typical urban environment, the general population is exposed to about 200 air pollutants or classes of air pollutants [1]. The concentrations of each pollutant (time-averaged over periods ranging from 15 minutes to a year) are functions of the emission rates of the pollutant, atmospheric chemistry, meteorology and local terrain, among other factors. The concentration levels of each of these pollutants therefore vary with time and location within the urban environment, independently, collinearly or antagonistically to each other. Adverse effects may be experience due to short-term exposures 
(exposures ranging from 15 minutes to several days) or prolonged exposure (months to years). The health endpoints associated with exposure to individual air pollutants may be the exacerbation of symptoms of asthma, cardiovascular disease, premature death, cancer or impairment of development. Individual susceptibility and the prevalence of health conditions that predispose the exposed population to an adverse response further complicate attempts to estimate the health risk associated with air pollution [2]. Thus the task of conveying to the general population this complex relationship between exposure to air pollution and ill health in a simple but accurate manner is formidable.

A number of countries (about 20) employ some type of air pollution index, usually applied at the urban (city) scale, to communicate the quality of their air. These air pollution (or air quality) index systems are a simplified (and perhaps simplistic) method of communicating the potential health impacts of the prevailing air pollution levels. In the overwhelming majority of examples, the air quality of air pollution index is based on the ambient concentrations of the classical or criteria (US terminology) pollutants - sulphur dioxide (SO2), particulate matter (PM10), nitrogen dioxide (NO2), carbon monoxide $(\mathrm{CO})$ and the secondary pollutant ozone $(\mathrm{O} 3)$. In a few cases, benzene and $\mathrm{PM}_{2.5}$ are considered in the calculation of the index.

Most of these systems rely on relating measured (monitored) or predicted concentrations of air pollutants to a numerical scale, for example ranging from 0 and 100. This scale may be enhanced by verbal descriptors such as high or moderate. The advantage of such a system is that the public does not have to interpret a number of different concentrations - one for each pollutant. They also do not need to recall that, the health effects of, for example $1 \mathrm{ppm}$ of ozone is very different from those of $1 \mathrm{ppm}$ of carbon monoxide.

The simplistic use of a single index to reflect air pollution levels of several pollutants creates several difficulties. Different pollutants may have different health endpoints, information that may be lost through the use of a single index. Members of the public may also find it difficult to obtain details of how to translate a unified pollution index back into the disaggregated 'real' pollutant levels. In addition, it can be difficult to use a single index to compare pollutant levels with national or international standards or guidelines, or with indices used in other countries.

The Dynamic Air Pollution Prediction System (DAPPS) is a research project involving a consortium of four groups - the CSIR (the lead partner), South African
Weather Service, Peninsula Technikon and SRK Consulting, and is funded by the Department of Arts, Culture, Science and Technology via the National Research Foundation's Innovation Fund. The DAPPS is intended to address the need for integrated publicly accessible information on urban scale air pollution, and its potential health impacts.

DAPPS involves the development and integration of the following elements: Downscaling the current numerical urban-scale weather prediction to a finer spatial (initially $1.7 \mathrm{~km}$ ) and temporal resolution (1 hour), and establishing a comprehensive air pollutant emission inventory that will include industrial, motor vehicle, aircraft and domestic emissions, and temporal variations in these emissions. The enhanced meteorological data and the emission inventory data will be used as inputs into a photochemical dispersion model, the Comprehensive Air Quality Model with Extensions (CAMx), to produce air pollution fields (isopleths) for the forecast meteorology.

The development of an Air Pollution Index (API) or Indices that reflect the potential health impacts of the air pollution fields predicted by DAPPS is a key aspect of the system. The basic concept of this index is that of using a combination of (DAPPS) modelled pollutant concentrations and published exposure-response functions to derive a numerical scale specific to each of the pollutants included in the Index.

The general factors that were to be considered in constructing an API are:

- The list of pollutants to be considered, and the averaging period or periods to be used for each pollutant.

- The use of monitored (measured) or modeled data as a measure of exposure. (In practice, modeled values include the use of measured data, usually used to calibrate and verify modeling outputs.)

- Health endpoints to be considered, including a consideration of the likely response time of exposure to the air pollutants. Exposure to pollutants such as $\mathrm{SO}_{2}$ and ozone may have health effects within hours or days whereas carcinogens have a latency period of years; some pollutants (including $\mathrm{SO}_{2}$ and $\mathrm{PM}$ ) may have adverse effects due to both short-term and long-term exposure.

- Whether the additive or synergistic effects of exposure to a combination of pollutants would be considered or not. 
- The exposure-response relationships to be used for each pollutant and in relation to each health endpoint.

- The basis for normalizing the data, including a consideration of the 'toxicological model' to be used, and the relative scale to be used. In other words, the methods to be used to establish an equivalence of harm for different pollutants, with different health endpoints and exposureresponse relationships.

- The overall method(s) (algorithm(s)) to be used to calculate the Index, including a consideration of whether a single index should be calculated for all pollutants or one for each pollutant.

- The number of people that are likely to be exposed to the air pollution

- The distribution of vulnerable or sensitive subgroups within the exposed population.

The pilot site is the City of Cape Town.

\section{International Practice}

A number of countries (including the United Kingdom (UK), the United States of America (USA), Belgium, France, Spain, Finland, Sweden, Canada, Mexico, Australia, New Zealand, Hong Kong, Singapore, Malaysia, Thailand, China, Macau, Indonesia, Taiwan) employ some type of air pollution index to communicate the quality of their air. This paper will focus on that used in the United Kingdom and the USA, with brief reference to the methodologies used by other countries.

\section{United Kingdom [3]}

A system of banding of air quality, introduced in the UK in 1990, was replaced in 1997 with one describing levels of air pollution [4]. Both systems were based on an understanding of the effects of air pollutants on health. A public consultation process before the change revealed that the public felt it was easier to understand a system that dealt with the levels of air pollution than one which described air quality. The new system was therefore related to the UK Air Quality Standards.
Bands are based on effects on health, offering a broad guide to effects on health rather than sudden changes in effects. Rather, a gradual increase in risk of adverse effects on health is expected as concentrations of the pollutants increase.

Originally this system consisted of a four-band system, indicated as low, moderate, high and very high. A consumer survey indicated that the public did not like the sudden jump from moderate to high; they much preferred the 1-10 index scale. This type of scale was already in use for describing pollen and solar UV radiation so it made sense to adopt it for air pollution as well. The approach used was to simply break each of the low, moderate, high bands down into 3 smaller increments, and keeping the same very high threshold which became index 10 .

The pollutants addressed in the UK system are $\mathrm{NO}_{2}$, $\mathrm{SO}_{2}, \mathrm{CO}, \mathrm{PM}_{10}$ and $\mathrm{O}_{3}$. The rationales behind the breakpoints for these different compounds, are as follows:

- the first breakpoint (low to moderate) are referred to as the standard threshold. This breakpoint is determined by National Air Quality Standard as defined by UK Expert Panel on Air Quality Standards, adopted by the Government in the National Air Quality Strategy. At this level, effects are unlikely to be noticed, even for a sensitive population.

- At the second breakpoint (moderate to high), or the information threshold, mild effects, unlikely to require action, may be noticed by sensitive individuals.

- At the third breakpoint (high to very high), referred to as the alert threshold, significant effects could be noticed by sensitive people. Information and emission control measures must be taken to protect population

- Above population alert threshold: effects for sensitive people become worse.

The UK index system is summarised in Table 1. 
Table 1: Boundaries Between Index Points for Each Pollutant in the UK system

\begin{tabular}{|c|c|c|c|c|c|c|c|c|c|c|}
\hline \multirow[t]{3}{*}{ Band } & \multirow[t]{3}{*}{ Index } & \multirow{2}{*}{\multicolumn{2}{|c|}{\begin{tabular}{|l|} 
Ozone \\
$\begin{array}{l}8 \text { hourly or hourly } \\
\text { mean* }\end{array}$ \\
\end{tabular}}} & \multicolumn{4}{|c|}{ Nitrogen Dioxide Sulphur Dioxide } & \multicolumn{2}{|c|}{ Carbon Monoxide } & \begin{tabular}{|l} 
PM10 \\
Particles
\end{tabular} \\
\hline & & & & \multicolumn{2}{|c|}{ hourly mean } & \multicolumn{2}{|c|}{15 minute mean } & \multicolumn{2}{|c|}{8 hour mean } & $\begin{array}{ll}24 & \text { hou } \\
\text { mean } & \end{array}$ \\
\hline & & $\mu \mathrm{gm}-3$ & ppb & ugm-3 & $\mathrm{ppb}$ & ugm-3 & $\mathrm{ppb}$ & mgm-3 & ppm & $\mu \mathrm{gm}-3$ \\
\hline \multicolumn{11}{|l|}{ Low } \\
\hline & 1 & $0-32$ & $0-16$ & $0-95$ & $0-49$ & $0-88$ & $0-32$ & $0-3.8$ & $0.0-3.2$ & $0-16$ \\
\hline & 2 & $33-66$ & $17-32$ & 96-190 & $50-99$ & $89-176$ & $33-66$ & $3.9-7.6$ & $3.3-6.6$ & $17-32$ \\
\hline & 3 & $67-99$ & $33-49$ & $191-286$ & $100-149$ & $177-265$ & $67-99$ & $7.7-11.5$ & $6.7-9.9$ & $33-49$ \\
\hline \multicolumn{11}{|c|}{ Moderate } \\
\hline & 4 & 100-126 & $50-62$ & $287-381$ & 150-199 & 266-354 & $100-132$ & 11.6-13.4 & $10.0-11.5$ & 50-57 \\
\hline & 5 & $127-152$ & $63-76$ & $382-476$ & $200-249$ & $355-442$ & $133-166$ & $13.5-15.4$ & $11.6-13.2$ & $58-66$ \\
\hline & 6 & $153-179$ & $77-89$ & 478-572 & $250-299$ & $443-531$ & $167-199$ & $15.5-17.3$ & $13.3-14.9$ & 67-74 \\
\hline \multicolumn{11}{|c|}{ High } \\
\hline & 7 & $180-239$ & 90-119 & \begin{tabular}{|l|}
$573-635$ \\
\end{tabular} & $300-332$ & $532-708$ & $200-266$ & $17.4-19.2$ & $15.0-16.5$ & $75-82$ \\
\hline & 8 & 240-299 & $120-149$ & $363-700$ & $333-366$ & 709-886 & $267-332$ & $19.3-21.2$ & 16.6-18.2 & 83-91 \\
\hline & 9 & $300-359$ & $150-179$ & $701-763$ & $367-399$ & $887-1063$ & $333-399$ & $21.3-23.1$ & $18.3-19.9$ & 92-99 \\
\hline \multicolumn{11}{|c|}{ Very High } \\
\hline & 10 & $\begin{array}{ll}360 & 01 \\
\text { more }\end{array}$ & r $\begin{array}{ll}180 & \text { or } \\
\text { more }\end{array}$ & \begin{tabular}{|ll}
764 & or \\
more
\end{tabular} & $\begin{array}{ll}400 & \text { or } \\
\text { more }\end{array}$ & $\begin{array}{l}1064 \\
\text { more }\end{array}$ & $\begin{array}{ll}400 & 0 \\
\text { more }\end{array}$ & $\begin{array}{l}23.2 \\
\text { more }\end{array}$ & $\begin{array}{l}20 \\
\text { more }\end{array}$ & $\begin{array}{l}100 \\
\text { more }\end{array}$ \\
\hline
\end{tabular}

Descriptors given on the UK's NETCEN archive website [5]:

- When air pollution is LOW (1-3) effects unlikely to be noticed even by those sensitive to air pollution.

- When air pollution is MODERATE (4-6) sensitive people may notice mild effects but these are unlikely to need action.

- When air pollution is HIGH (7-9) sensitive people may notice significant effects and may need to take action.

- When air pollution is VERY HIGH (10) effects on sensitive people, described for HIGH pollution, may worsen.

\section{United States of America}

A nationally uniform air quality index (AQI), originally called the Pollutant Standard Index (PSI) [6] was established in 1976, for use by State and local agencies on a voluntary basis.

The intended advantages of this index are that is:

- it sends a clear and consistent message to the public by providing nationally uniform information on air quality;

- $\quad$ it is keyed to the NAAQS and the significant harm level (SHL) which have a scientific basis relating air quality and public health;
- $\quad$ it is simple and easily understood by the public;

- it provides a basis for accommodating changes to the NAAQS; and

- it can be forecasted to provide advance information on air quality [6].

The PSI or AQI, as it is currently referred to, includes indices for $\mathrm{O}_{3}, \mathrm{PM}, \mathrm{CO}, \mathrm{SO}_{2}$, and $\mathrm{NO}_{2}$, which relate ambient pollutant concentrations to index values on a scale from 0 to 500 [7]. This represents a very broad range of air quality, from pristine air to air pollution levels that present imminent and substantial endangerment to the public. The index is normalized across pollutants by defining an index value of 100 as the numerical level of the primary NAAQS for each pollutant and an index value of 500 as the SHL. Such index values serve to divide the index into categories, with each category being identified by a simple informative descriptor. The descriptors are intended to convey to the public information about how air quality within each category relates to public health, with increasing public health concerns being conveyed as the categories range to the upper end of the scale.

Table 2 summarises the USA index system. 
Table 2: Breakpoints for the USA Air Quality Index [8, 7]

\begin{tabular}{|c|c|c|c|c|c|c|c|c|}
\hline \multicolumn{7}{|c|}{ These breakpoints -- } & \multirow{2}{*}{$\begin{array}{l}\text { Equal } \\
\text { these } \\
\text { PSIs }\end{array}$} & \multirow[b]{2}{*}{ Categories } \\
\hline $\begin{array}{l}\mathrm{O}_{3} \text { (ppm) } \\
\text { 8-hour }\end{array}$ & $\begin{array}{l}\mathrm{O}_{3} \text { (ppm) } \\
\text { 1-hour }^{1}\end{array}$ & $\begin{array}{l}24 \mathrm{~h} \mathrm{PM}_{10} \\
\left(\mu \mathrm{g} / \mathrm{m}^{3}\right)\end{array}$ & $\begin{array}{l}24 \mathrm{~h} \mathrm{PM}_{2.5} \\
\left(\mu \mathrm{g} / \mathrm{m}^{3}\right)\end{array}$ & $\begin{array}{l}8 \mathrm{~h} \\
\mathrm{CO} \\
(\mathrm{ppm})\end{array}$ & $\begin{array}{l}24 \mathrm{~h} \\
\mathrm{SO}_{2} \text { (ppm) }\end{array}$ & 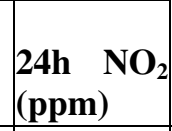 & & \\
\hline 0.000 & - & & & & 0.000 & & & \\
\hline 0.064 & - & $0-54$ & $0.0-15.4$ & $0.0-4.4$ & 0.034 & (2) & $0-50$ & Good \\
\hline 0.065 & - & & & & 0.035 & & & \\
\hline 0.084 & - & $55-154$ & $15.5-40.4$ & $4.5-9.4$ & 0.144 & (2) & $51-100$ & Moderate \\
\hline 0.085 & $-0.125-$ & & & & 0.145 & & & Unhealthy for \\
\hline 0.104 & 0.164 & $155-254$ & $40.5-65.4$ & $9.5-12.4$ & 0.224 & (2) & $101-150$ & sensitive groups \\
\hline 0.105 & -0.165 & - & $65.5^{4}$ & $-12.5-$ & -0.225 & & & \\
\hline 0.124 & 0.204 & $255-354$ & 150.4 & 15.4 & 0.304 & (2) & $151-200$ & Unhealthy \\
\hline 0.125 & -0.205 & - & $150.5^{4}-$ & 15.5 & -0.305 & -0.65 & & \\
\hline 0.374 & 0.404 & $355-424$ & 250.4 & 30.4 & 0.604 & 1.24 & $201-300$ & Very unhealthy \\
\hline & 0.405 & - & $250.5^{4}-$ & 30.5 & -0.605 & -1.25 & & \\
\hline$(3)$ & 0.504 & $425-504$ & 350.4 & 40.4 & 0.804 & 1.64 & $301-400$ & \\
\hline & 0.505 & & $350.5^{4}-$ & 40.5 & -0.805 & -1.65 & & \\
\hline (3) & 0.604 & $505-604$ & 500.4 & 50.4 & 1.004 & 2.04 & $401-500$ & Hazardous \\
\hline
\end{tabular}

1 Areas are generally required to report the AQI based on 8-hour ozone values. However, there are a small number of areas where an AQI based on 1-hour O3 values would be more precautionary. In these cases, in addition to calculating the 8-hour $\mathrm{O} 3$ index value, the 1-hour $\mathrm{O} 3$ index value may be calculated and the maximum of the two reported.

2 NO2 has no short-term NAAQS and can generate a AQI only above a AQI value of 200

3 8-hour O3 values do not define higher AQI values (>=301). AQI values of 301 or higher are calculated with 1-hour $\mathrm{O} 3$ concentrations

4 If a different SHL (significant harm level) for PM2.5 is promulgated, these numbers will change accordingly.

Index values, descriptors and colours associated with the AQI are indicated in Table 4.

Table 4. Index values, descriptors and associated colours of the AQI [6].

\begin{tabular}{|c|c|c|c|}
\hline Index values & Descriptor & Colour & Purpose \\
\hline $0-50$ & Good & Green & Convey positive message about air quality \\
\hline $51-100$ & Moderate & Yellow & $\begin{array}{l}\text { Convey message that daily air quality is acceptable from } \\
\text { public health perspective, but every day in this range could } \\
\text { result in potential for chronic health effect; and for O3, } \\
\text { convey a limited health notice for extremely sensitive } \\
\text { individuals. }\end{array}$ \\
\hline $101-150$ & $\begin{array}{l}\text { Unhealthy for } \\
\text { sensitive groups }\end{array}$ & Orange & Health message for members of sensitive groups \\
\hline $151-200$ & Unhealthy & Red & $\begin{array}{l}\text { Health advisory of more serious effects for sensitive groups } \\
\text { and notice of possible effects for general population when } \\
\text { appropriate. }\end{array}$ \\
\hline $201-300$ & Very unhealthy & Purple & $\begin{array}{l}\text { Health alert of more serious effects for sensitive groups and } \\
\text { the general population. }\end{array}$ \\
\hline 301and above & Hazardous & Maroon & Health warnings of emergency conditions \\
\hline
\end{tabular}


The US Environmental Protection Agency (US EPA) also issues a set of pollutant specific advisory wording for each index band.

Although the UK and USA index systems are attempting to achieve the same objective of presenting air pollution (or quality) data using an index system, the two systems differ in several respects, making direct comparison difficult. The UK index system has values from 0 to 10 , with 10 representing all concentrations greater than the upper bound for the 8 to 9 band; the US system has values from 0 to 500 , with 500 representing all concentrations greater than the upper bound for the 451-500 band. In the cases of SO2 and NO2, different time-averaged values are used in the two jurisdictions. Ozone $1 \mathrm{~h}$ and $8 \mathrm{~h}$ averages are used in both cases, but these values are used somewhat differently. The US EPA includes PM2.5 in their index system whereas the UK does not. Only PM10 and CO are treated similarly.

The breakpoints between the 'low' and 'moderate' bands (between index values 3 and 4) in the UK system, for PM10 and CO, are $49 \mathrm{ug} / \mathrm{m} 3$ and $9.9 \mathrm{ppm}$ respectively. The US value between 'good' and 'moderate' for PM10 is $54 \mathrm{ug} / \mathrm{m} 3$, similar to the UK value of $49 \mathrm{ug} / \mathrm{m} 3$ between 'low' and 'moderate', but the corresponding US values for $\mathrm{CO}$ is $4.4 \mathrm{ppm}$, half the UK value. For ozone, the UK 'low' to moderate' breakpoint is 49-50ppb; for the US the $8 \mathrm{~h}$ average breakpoint between 'good' and moderate is $64-65 \mathrm{ppb}$. There is thus a lack of alignment for ozone as well. The other pollutants cannot be directly compared because different averaging periods are used in the two countries. Thus both the index values and the more general descriptors of 'low', moderate', 'high' and 'very high' in the UK cannot readily be aligned with the US descriptors of 'good', 'moderate' etc.

In several countries, including the UK and the USA, the descriptor of the air quality for the day is taken as the highest reached by any pollutant of the group that is monitored. If only one pollutant reaches the 'moderate band' levels of air pollution, the descriptor used is moderate. If, eg, four pollutants all reach the moderate band air pollution, is again, described as moderate. In the second case, a more significant health effect may however be expected in comparison to the former [4].

\section{Air pollutants and averaging periods to be included in the DAPPS APIs \\ Specific criteria for selection:}

- Health hazard (either as a primary pollutant or as a precursor to the formation of a secondary pollutant that is a recognised health hazard);

- Released in significant quantities in the study area;

- DAPPS modelling capabilities;

- Availability of exposure response relationships;

- Requested by public;

- International practice;

- Response to acute ( $<=1$ hour) to short-term $(<=24$ hours) time-averaged exposures, with response occurring within 3 days of exposure;

In essence the DAPPS is attempting to provide close-toreal-time information on current and short-term future air pollution throughout the modelling domain; the Air Pollution Index (or indices) would indicate the likely short-term health impacts of the predicted pollution levels. While the DAPPS may predict ambient concentrations of pollutants with long-term health consequences (such as lead and benzene), these pollutant concentrations would not be included in the calculation of the (short-term) APIs. This does not preclude the provision of potential health impact information (for example by comparing predicted daily values against guideline values) for pollutants with a latency period (carcinogens) or cumulative action (lead) as part of the overall DAPPS system.

Based on the above criteria, an inclusive approach was, in the interim, adopted for the selection of pollutants and averaging periods, as reflected in Table 3. A 15minute time averaged value for $\mathrm{SO} 2$ was not included because the minimum averaging period for the DAPPS is one hour. All other combinations of pollutant and time-averaging periods are to be found in one or other jurisdiction internationally.

Table 3: Pollutants and averaging periods to be included in the calculation of APIS

\begin{tabular}{|l|l|l|l|l|l|l|}
\hline Pollutant & SO2 & NO2 & O3 & PM10 & PM2.5 & CO \\
\hline Averaging periods & 1h, 24h & 1h, 24h & 1h, 8h & $24 h$ & $24 h$ & $1 \mathrm{~h}, 8 \mathrm{~h}$ \\
\hline
\end{tabular}


Review of approaches to establishing numerical values for air pollution indices

A number of countries, including the UK and the US use their national Air Quality Standards in order to normalise the air pollution indices. Although these national standards are explicitly health based, different interpretations of the available data, and different national priorities have lead in practice to differing air quality standards and consequently air pollution indices. The lack of a common approach and definition of air pollution indices was illustrated by the earlier comparison between the UK and US systems. At present there is no internationally accepted standard methodology for deriving air pollution (quality) indices.

In this paper we propose to discuss the use of a somewhat novel risk-based approach, based on the WHO/ECEH (World Health Organisation/ European Centre for Environment and Health) methodology for estimating the health impact of ambient air pollution [8].

\section{WHO Relative Risk values, health endpoints and exposure-response relationships}

The question of the exposure-response relationship for each of the pollutants may be approached from one of two perspectives: a risk based approach or a 'toxicological' approach that assumes that there is a threshold below which no adverse effects occur. The vast scientific literature on the relationship between exposure to air pollution and health has been reviewed and summarised in a number of WHO publications, including Air Quality Guidelines (2000) [9]. Of the pollutants under consideration for the API (SO2, NO2, PM10, PM2.5, O3 and CO), the PM10, PM2.5 and ozone do not do not have an apparent threshold value below which the risk of adverse health effect is zero. Continuing research indicates that $\mathrm{SO} 2$ and NO2 may not have threshold values either [10]. In other words, except for $\mathrm{CO}$, exposure to these pollutants carries a finite risk of an adverse health effect.

The WHO has also published a technical report proposing a procedure for Health Impact Assessment in the EU [8] (WHO HIA report), using Relative Risk factors for $\mathrm{SO} 2, \mathrm{NO} 2, \mathrm{PM} 10, \mathrm{PM} 2.5$ and $\mathrm{O} 3$ in relation to a range of health endpoints. The data and methodologies in these publications (and the relevant primary sources) are under evaluation for use for the development of the DAPPS APIs.

Tables 1 and 2 have been adapted from Annex A of the WHO HIA report. These tables illustrate the relative risks of respiratory and other diseases and health endpoints associated with increasing air pollution.

The health endpoint 'Total mortality' is the only one that is common to all the pollutants and time-averaged values under consideration in developing the DAPPS APIs. One approach under evaluation is to use a common increment of risk attributable to each pollutant/ time averaged value combination under a given exposure scenario to establish breakpoints for the APIs. 
Incidence and relative risk estimates (RR) for various pollutants and health outcomes (WHO default values) Table 1: RR per $10 \mathrm{ug} / \mathrm{m}^{3}$ increase of daily averages of PM10, PM2.5, SO2

\begin{tabular}{|c|c|c|c|c|c|c|c|}
\hline HEALTH ENDPOINT & Incidence & $\begin{array}{c}\text { PM10 } \\
\text { (24h ave.) }\end{array}$ & & $\begin{array}{c}\text { PM2.5 } \\
\text { (24h ave.) }\end{array}$ & & $\begin{array}{c}\text { SO2 } \\
\text { 24h ave.) }\end{array}$ & \\
\hline & $\begin{array}{c}\text { Per } \\
100000\end{array}$ & $\mathbf{R R}$ & $\mathbf{R r S}$ & $\mathbf{R R}$ & RrS & & $\operatorname{RrS}$ \\
\hline \multicolumn{8}{|l|}{ MORTALITY } \\
\hline \multirow[t]{2}{*}{ Total mortality } & 1013 & 1.0074 & 3 & 1.015 & 3 & 1.004 & 2 \\
\hline & & $(1.0062-1.0086)$ & & $(1.011-1.019)$ & & $(1.003-1.0048)$ & \\
\hline \multirow[t]{2}{*}{ CardiovascularMortality } & 497 & 1.008 & 2 & & & 1.008 & 1 \\
\hline & & $(1.005-1.018)$ & & & & $(1.002-1.012)$ & \\
\hline \multirow[t]{2}{*}{ Respiratory Mortality } & 66 & 1.012 & 2 & & & 1.01 & 1 \\
\hline & & $(1.008-1037)$ & & & & $(1.006-1.014)$ & \\
\hline \multicolumn{8}{|l|}{ MORBIDITY } \\
\hline \multirow[t]{2}{*}{$\begin{array}{l}\text { Hospital Admissions Respiratory } \\
\text { Disease }\end{array}$} & 1260 & 1.008 & 3 & & & & \\
\hline & & \begin{tabular}{|l}
$(1.0048$ \\
$1.0112)$
\end{tabular} & & & & & \\
\hline \multicolumn{8}{|l|}{\begin{tabular}{|l|l|} 
Hospital Admissions Respiratory & \\
Dis $<15$ Years
\end{tabular}} \\
\hline \multirow[t]{2}{*}{$\begin{array}{l}\text { Hospital Admissions Respiratory } \\
\text { Dis 15-64 years }\end{array}$} & 66 & & & & & 1.0018 & 3 \\
\hline & & & & & & $(1-1.005)$ & \\
\hline \multirow[t]{2}{*}{$\begin{array}{l}\text { Hospital Admissions Respiratory } \\
\text { Dis 65+ Years }\end{array}$} & & & & & & 1.004 & 3 \\
\hline & & & & & & $(1.001-1.009)$ & \\
\hline \multirow[t]{2}{*}{$\begin{array}{l}\text { Hospital Admissions Asthma }<15 \\
\text { Years }\end{array}$} & 100 & & & & & 1.015 & 1 \\
\hline & & & & & & $(1.0052-1.025)$ & \\
\hline \multirow[t]{2}{*}{$\begin{array}{l}\text { Hospital Admissions Asthma }>15- \\
64 \text { Years }\end{array}$} & 66 & & & & & 1 & 1 \\
\hline & & & & & & $(1-1.0068)$ & \\
\hline \multirow[t]{2}{*}{ Hospital Admissions COPD } & 101.4 & & & & & 1.0044 & 1 \\
\hline & & & & & & $(1-1.011)$ & \\
\hline \multirow[t]{2}{*}{$\begin{array}{l}\text { Hospital Admissions } \\
\text { Cardiovescular Disease }\end{array}$} & 436 & 1.009 & 3 & & & & \\
\hline & & $(1.006-1.013)$ & & & & & \\
\hline \multicolumn{8}{|l|}{$\begin{array}{l}\text { Hospital Admissions Congestive } \\
\text { Heart Elderly }\end{array}$} \\
\hline \multirow[t]{2}{*}{ Acute Myocardial Infarction } & 132 & & & & & 1.0064 & 2 \\
\hline & & & & & & $(1.0026-1.0101)$ & \\
\hline \multicolumn{8}{|l|}{ Chronic Bronchitis } \\
\hline \multicolumn{8}{|l|}{ Chronic Bronchitis $>25$ Years } \\
\hline \multicolumn{8}{|l|}{ Acute Bronchitis $<$ f5 Years } \\
\hline \multirow[t]{2}{*}{ Asthma Attacks Children } & & 1.051 & 2 & & & & \\
\hline & & $(1.047-1.055)$ & & & & & \\
\hline \multirow[t]{2}{*}{ Asthma Attacks Adults } & & 1.004 & 2 & & & & \\
\hline & & $(1-1.008)$ & & & & & \\
\hline
\end{tabular}

Value of Relative Risk Strength (RrS): 1 Weak 2 Medium 3 Good

The figures in bold represent the average Relative Risk, figures below the average RR (...) represent the $95 \%$ confidence interval. 
Table 2: $\mathrm{RR}$ per $10 \mathrm{ug} / \mathrm{m}^{3}$ increase of 8-hour max and 1-hour max for $\mathrm{O}_{3}$ and daily average and 1-hour max for $\mathrm{NO}_{2}$

\begin{tabular}{|c|c|c|c|c|c|c|c|c|c|}
\hline $\begin{array}{c}\text { HEALTH } \\
\text { ENDPOINT }\end{array}$ & Incidence & $\begin{array}{c}O_{3} \\
8 \mathrm{hr} \text { max } \\
\end{array}$ & & $\begin{array}{c}O_{3} \\
1 \mathrm{hr} \text { max } \\
\end{array}$ & & $\begin{array}{c}\mathrm{NO}_{2} \\
\text { daily avg. }\end{array}$ & & $\begin{array}{c}\mathrm{NO}_{2} \\
1 \mathrm{hr} \text { max. }\end{array}$ & \\
\hline & $\begin{array}{c}\text { Per } \\
100000\end{array}$ & $\mathbf{R R}$ & $\operatorname{RrS}$ & $\mathbf{R R}$ & RrS & $\mathbf{R R}$ & RrS & $\mathbf{R R}$ & $\operatorname{RrS}$ \\
\hline \multicolumn{10}{|l|}{ MORTALITY } \\
\hline Total Mortality & 1013 & 1.0051 & 1 & 1.0046 & 3 & & & 1.003 & 2 \\
\hline & & $\begin{array}{l}(1.00023- \\
1.0078)\end{array}$ & & $\begin{array}{l}(1.0028- \\
1.0066)\end{array}$ & & & & $\begin{array}{ll}1.0018 & - \\
1.0034) & -\end{array}$ & \\
\hline Cardiovascular Mortality & 497 & 1.004 & 2 & 1.004 & 2 & 1.002 & 2 & 1.002 & 2 \\
\hline & & $(1-1.006)$ & & $(1002-1.006)$ & & $(1-1.004)$ & & $(1-1002)$ & \\
\hline RespiratoryMortality & 66 & 1.0126 & 2 & 1.008 & 2 & & & & \\
\hline & & $\begin{array}{l}(1.0046- \\
1.0208)\end{array}$ & & $1004-1012$ & & & & & \\
\hline MORBIDITY & & & & & & & & & \\
\hline \begin{tabular}{|l|l} 
Hospital Admissions \\
Respiratory Disease
\end{tabular} & 1260 & & & & & & & & \\
\hline \begin{tabular}{|ll} 
Hospital & Admissions \\
Respiratory & Dis $<15$ Years \\
\end{tabular} & 100 & & & & & & & & \\
\hline \begin{tabular}{lll} 
Hospital & \multicolumn{2}{c|}{ Admissions } \\
Respiratory & Dis & $15-64$ \\
Years & & \\
\end{tabular} & 66 & 1.0062 & 2 & 1.0038 & 2 & 1.002 & 1 & 1.0008 & 1 \\
\hline & & $\begin{array}{ll}(1.0026 & - \\
0098) & \end{array}$ & & $(1.001-10066)$ & & $(1-1.0072)$ & & $(1-10022)$ & \\
\hline 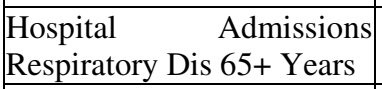 & & 1.0076 & 2 & 1.0062 & 2 & 1.0038 & 1 & 1.001 & 1 \\
\hline & & $\begin{array}{l}(1.0036 \\
10116)\end{array}$ & & $\begin{array}{ll}(1 & 003 \\
1.0094)\end{array}$ & & $(1-1.012)$ & & $(1-1.0066)$ & \\
\hline \begin{tabular}{|ll}
$\begin{array}{l}\text { Hospital } \\
\text { Asthma }\end{array}$ & Admissions \\
\end{tabular} & 100 & 1.000 & 1 & 1.0012 & 1 & 1.0062 & 1 & 1.0024 & 1 \\
\hline$<15$ Years & & $(1-10076)$ & & $(1-1.0074)$ & & $(1.0012-1.0098)$ & & $(1-1,005)$ & \\
\hline $\begin{array}{|ll|}\text { Hospital } & \text { Admissions } \\
\text { Asthma } & \\
\end{array}$ & 66 & 1.007 & 1 & 1.003 & 1 & 1.0058 & 1 & 1.0022 & 1 \\
\hline$>15-64$ Years & & $(1-1.0288)$ & & $(1-1.0156)$ & & $(1.0006-1.011)$ & & $(1-1.0044)$ & \\
\hline $\begin{array}{ll}\text { Hospital Admissions } \\
\text { COPD }\end{array}$ & $\begin{array}{l}\mathrm{s} \\
101.4 \\
\end{array}$ & 1.0086 & 2 & 1.0068 & 2 & 1.0038 & 2 & 1.0026 & 2 \\
\hline & & $\begin{array}{l}(1.0044 \\
1.013)\end{array}$ & & $\begin{array}{l}(1.0022- \\
1.0094)\end{array}$ & & $\begin{array}{l}(1.0004 \\
1.0094) \\
\end{array}$ & & $\begin{array}{l}(1.0006 \\
10044)\end{array}$ & \\
\hline $\begin{array}{l}\text { Hospital Admissions } \\
\text { Cardiovascular Disease }\end{array}$ & 436 & & & & & & & & \\
\hline $\begin{array}{lr}\text { Hospital Admissions } \\
\text { Congestive Heart Elderly }\end{array}$ & 122 & & & & & & & & \\
\hline $\begin{array}{|ll|}\text { Acute } & \text { Myocardial } \\
\text { Infarction } & \\
\end{array}$ & 132 & & & & & 1.0036 & 1 & & \\
\hline & & & & & & $\begin{array}{l}(1.0015 \\
1.0084)\end{array}$ & & & \\
\hline
\end{tabular}

The proportion of the health impact (Total mortality, asthma attacks in children, etc.) attributable to a given exposure (pollutant-time combination) in a given population may be calculated using:

$\mathrm{AP}=\operatorname{SUM}\{[\mathrm{RR}(\mathrm{c})-1] * \mathrm{P}(\mathrm{C})\} / \operatorname{SUM}[\mathrm{RR}(\mathrm{C}) * \mathrm{p}(\mathrm{c})]$,

where: $R R(c) \quad$ - relative risk for the health outcome in category $\mathrm{c}$ of exposure, $\mathrm{p}(\mathrm{c})$ - proportion of the population in category $\mathrm{c}$ of the exposure and

AP - Attributable Proportion (of the health outcome to the given exposure).

The number of cases $\mathrm{I}_{\mathrm{E}}$ attributable to exposure to air pollutants, for a baseline frequency I of the selected health outcome may be calculated from:

$$
\mathrm{I}_{\mathrm{E}}=\mathrm{I}^{*} \mathrm{AP} \text {. }
$$


The estimate of the number of cases (for a given pollution level) is thus clearly dependent on the baseline frequency and the relative risk factors; both these factors may vary from city to city or country to country.

The data given in Tables 1 and 2 are by and large based on studies in Europe. Baseline incidence and Relative Risk values may be different in regions and/ or different populations, and may be different in South African cities, and may be different within different areas of a city. Nevertheless, this approach to health impact assessment may provide a systematic method for estimating breakpoints for the different pollutantaveraging time combinations. These tables imply that the relative risk is constant for a constant increment $\left(10 \mathrm{ug} / \mathrm{m}^{3}\right)$ in pollution levels.

The basis for developing the DAPPS API is provided by the data contained in Tables 1 and 2 together with the exposure-response relationships given by the WHO Guidelines for Air Quality.

The difficulty of reconciling the different exposureresponse relationships and health endpoints is illustrated by the ozone exposure data given in Figures 1 and 2 . (FEV1: Forced Expiratory Volume in 1 second, a measure of lung function.) There is a non-linear response of FEV1 to increasing ozone concentration compared with the apparently linear response against symptom exacerbation

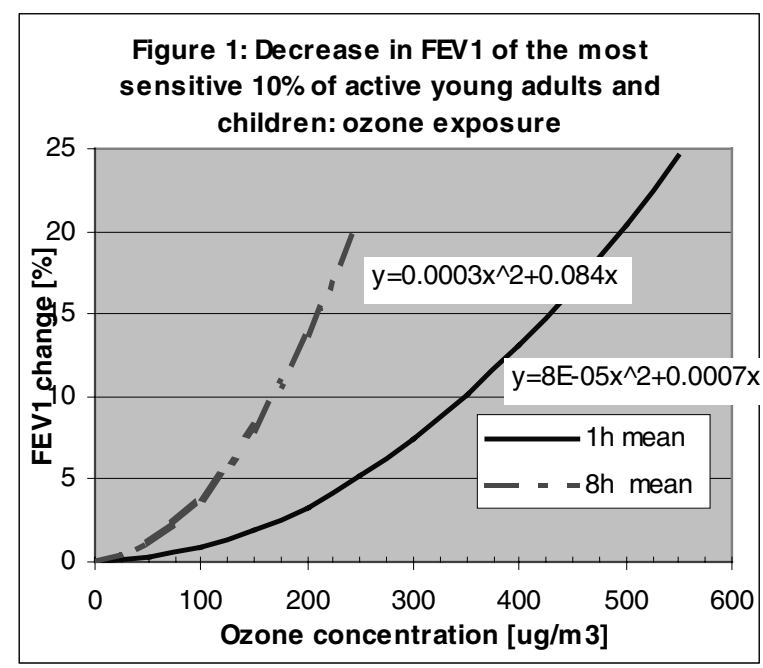

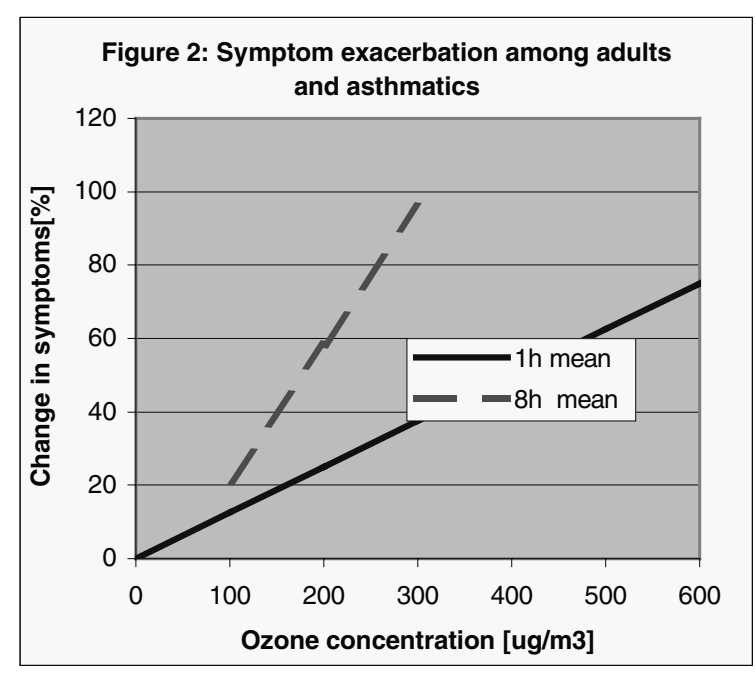

\section{Discussion}

The literature review showed that there is no internationally standardised methodology for constructing air pollution indices. The UK and US systems are similar in concept but differ substantially in implementation. The two systems cannot easily be aligned with each other to form the basis for a South African Air Pollution Index system.

The World Health Organisation methodology for a health risk assessment associated with air pollution potentially provides a methodology for construction the APIs, but further work is required to assess the influence of city specific baseline frequencies of the air pollution related health outcomes and relative risk factors.

\section{Acknowledgements}

The DAPPS project is funded by the national Innovation Fund, administered by the National Research Foundation.

\section{References}

1 The US EPA regulates the Criteria Pollutants and about 180 'Toxics'

2 Guidelines for Air Quality, WHO, Geneva, 2000

3 http://www.airquality.co.uk/

4 Maynard RL and Coster SM. Informing the public about air pollution. 1999. In Air pollution and health. Holgate, Samet, Karen \& Maynard (eds).

5 http://www.airquality.co.uk/

6 EPA, 1998. Federal Register, Vol. 63, no 236. December 1998. Air quality index reporting: Proposed Rules.

7 EPA, 1999. Federal Register, Vol. 64, no 149. August 1999. Air quality index reporting; Final Rule. 
8 HEALTH IMPACT ASSESSMENT OF AIR POLLUTION IN THE WHO EOROPEAN REGION, WHO/Euro product no: 876.03.01 (50263446) (November 2001)

9 Guidelines for Air Quality, WHO, Geneva, 2000

10 Guidelines for Air Quality, WHO, Geneva, 2000 (Chapter 3) 